\title{
Core-modified octaphyrins: Syntheses and anion-binding properties
}

\author{
RAJNEESH MISRA ${ }^{\mathrm{a}}$, VENKATARAMANARAO G ANAND ${ }^{\mathrm{a}}$, HARAPRIYA RATH ${ }^{\mathrm{a}}$ and \\ TAVAREKERE K CHANDRASHEKAR* *a,b \\ ${ }^{a}$ Department of Chemistry, Indian Institute of Technology, Kanpur 208 016, India \\ ${ }^{\mathrm{b}}$ Present address: Regional Research Laboratory, Trivandrum 695 019, India \\ e-mail: tkc@iitk.ac.in
}

\begin{abstract}
In this paper, a brief review of the syntheses, characterization and anion-binding properties of core-modified octaphyrins is presented. It has been shown that the core-modified octaphyrins exhibit aromaticity both in solution and in solid state, confirming the validity of the $(4 n+2)$ Huckel rule for larger $\pi$-electron systems. Solid-state binding characteristics of TFA anions of two core-modified octaphyrins are also described.
\end{abstract}

Keywords. Anion binding; aromaticity; $34 \pi$ electrons; octaphyrin; oxidative coupling reactions.

\section{Introduction}

Octaphyrins are a class of expanded porphyrins in which eight pyrrolic/hetrocyclic rings are linked to one another through meso carbon bridges. The molecular structure, the number of $\pi$ electrons and the aromatic properties of the octaphyrins depend upon the number of meso carbon bridges and the nature of the hetrocyclic ring. For example, a series of octaphyrins are reported in the literature in which the number of meso carbon bridges varies from zero to eight $^{1-5}$ (figure 1).

Of the five octaphyrins shown in figure 1, only one $^{5}(\mathbf{5})$ shows aromaticity. The reason for the lack of aromaticity has been attributed to the flexibility of the macrocycle and the attainment of a "figure eight" conformation. One way of avoiding the figure eight conformation is to introduce sterically bulkier groups at the meso carbon bridges and to replace one or more of the pyrrolic rings by other hetrocyclic rings such as furan, thiophene, selenophene. Such modification leads to core-modified octaphyrins. ${ }^{6}$

Recently we have reported the syntheses and characterization of several core-modified octaphyrins $^{7}$ (9-11) which contain $34 \pi$ electrons and show aromatic behaviour. Single crystal X-ray structure of these molecules shows a complete planar structure accounting for the high aromatic nature. Around the same time Latos-Grazynski and co-workers ${ }^{8}$ also reported the synthesis of core-modified tetrathia-octa-

Dedicated to the memory of the late Professor Bhaskar G Maiya

*For correspondence phyrin 13 (figure 2) which shows figure eight conformation. These octaphyrins exist in both reduced and oxidized forms which are interconvertible. The oxidized form is formally a $36 \pi$-electron system and is antiaromatic, while the reduced form is $38 \pi$ electron and formally aromatic. In this paper, a brief survey of the synthetic methodologies used for synthesis of core modified octaphyrins is given and their anion-binding properties have been described.

\section{Syntheses}

Octaphyrin syntheses have been achieved by MacDonald, Rothenmund and oxidative coupling reactions. Nonplanar, nonaromatic octaphyrin was obtained by all the methods. Generally it has been observed that polycyclopyrroles undergo twisting, which is responsible for the loss of planarity. Therefore, arresting the twist in the molecule is a key step in sustaining the planar form. Also, an observation of previous syntheses on octaphyrins revealed that steric hindrance due to bulky substituents at the $\beta$-position of the pyrrole ring $^{2}$ causes deformation of the $\pi$ conjugated system out of planarity, and that such strain can be minimized if the steric strain is shifted to the meso carbons, making the meso substituents more orthogonal to the porphyrin plane. Furthermore, the presence of bigger atoms in the core might help to attain the desired planar conformation. We used these modifications and reported the first syntheses of $34 \pi$-electron planar aromatic octaphyrin ${ }^{6}$ by the simple oxidative coupling reaction of the corre- 
sponding tetrapyrromethane in the presence of 1 eq. of trifluoroacetic acid (TFA) catalyst in methylene chloride in an inert atmosphere, followed by chloranil oxidation in air. The octaphyrins was obtained in 4-9.6\% yield (scheme 1). Variation of acid concentration within the range of one equivalent did not affect the reaction, while acid concentration of two equivalents yielded more of corresponding rubyrin probably due to acidolysis of tetrapyrromethanes. ${ }^{9}$

Latos-Grazynski and co-workers ${ }^{8}$ used a different approach for the synthesis of $\mathbf{1 3}$. They used the wellknown condensation of thiophenediol and pyrrole, using methanesulphonic acid as the catalyst, followed by chloranil oxidation to get the required tetrathiaoctaphyrin (scheme 2). Both dihydrogenated and dehydrogenated forms have been characterized and the detailed NMR studies reveal that both these forms possess helical figure eight geometry.

UV-visible spectra of 9-11 in methylene chloride show typical porphyrinic nature in which intense Soret-type bands are observed in the region 590-

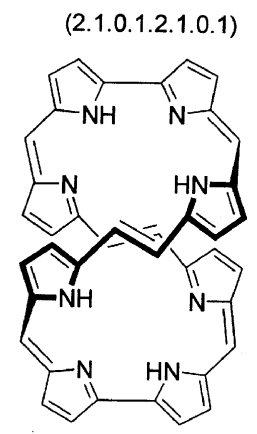

1

[36]Octaphyrin

$(1 \cdot 0.0 \cdot 0.1 \cdot 0.0 .0)$

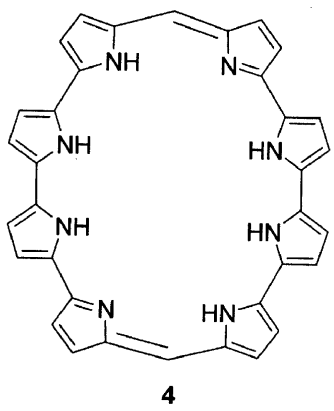

[32]Octaphyrin

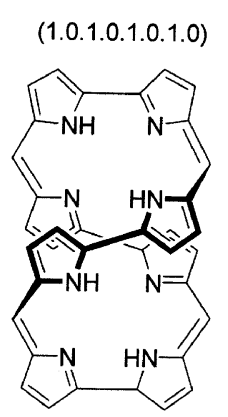

2

[32]Octaphyrin

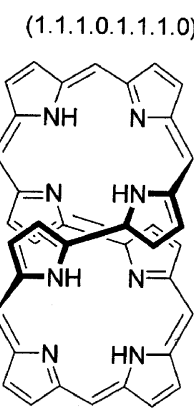

3

[34]Octaphyrin

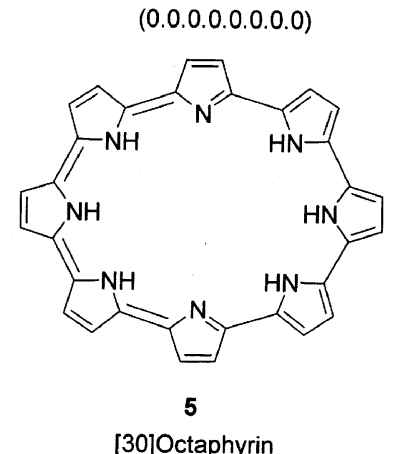

Figure 1. Molecular structure of known octaphyrins. The number shown above each structure represents the nature of its linkage.
$600 \mathrm{~nm}\left(\varepsilon \approx 10^{5}\right)$ and a series of $Q$ bands in the region 700-925 $\mathrm{nm}$. On diprotonation, these bands are shifted to lower energies confirming the meso aryl nature ${ }^{10}$ of octaphyrins. A typical absorption spectrum is shown in figure 3.

Detailed ${ }^{1} \mathrm{H}$ and 2D NMR studies on octaphyrins 9-11 provide important information about the aromaticity of the macrocycle. Proton resonances are observed both in the shielded and deshielded regions and exact chemical shift depends on the nature of the macrocycle and the hetero atom. An estimate of the diamagnetic ring current evaluated from the difference in chemical shifts of the most shielded and deshielded protons varies in the range 15-18 ppm, clearly suggesting the aromatic nature of octaphyrins in solution.

Solid state structures were confirmed from singlecrystal X-ray analysis. The structure clearly confirms the planar nature of the macrocycle except for the meso aryl substituents. Furthermore, for example, the structure of $\mathbf{1 0}$ reveals that one thiophene of each of the bithiophenes is inverted and the dihedral angle with respect to the mean plane defined by four meso carbons is $4 \cdot 67^{\circ}$. The aromatic nature of octaphyrin is revealed by the observation that $\mathrm{C}_{\alpha}-\mathrm{C}_{\beta}$ distances are greater than $\mathrm{C}_{\beta}-\mathrm{C}_{\beta}$ distances for both the thiophene and pyrrole rings.

\section{Anion binding}

Unlike parent porphyrins, expanded porphyrins by virtue of their bigger core size show interesting binding properties. In the protonated form, expanded porphyrins are known to bind anions, ${ }^{11}$ a property not exhibited by parent porphyrins. Protonation of
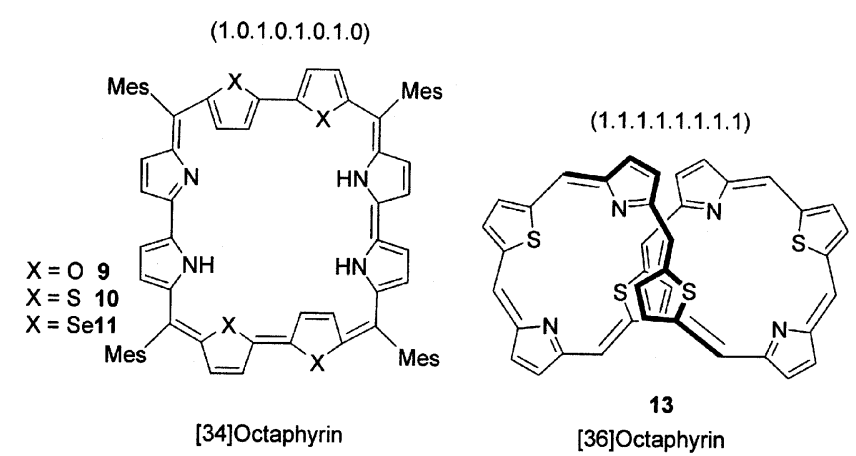

[36]Octaphyrin

Figure 2. Molecular structure of core-modified octaphyrins. The number shown above each structure represents the nature of its linkage. 


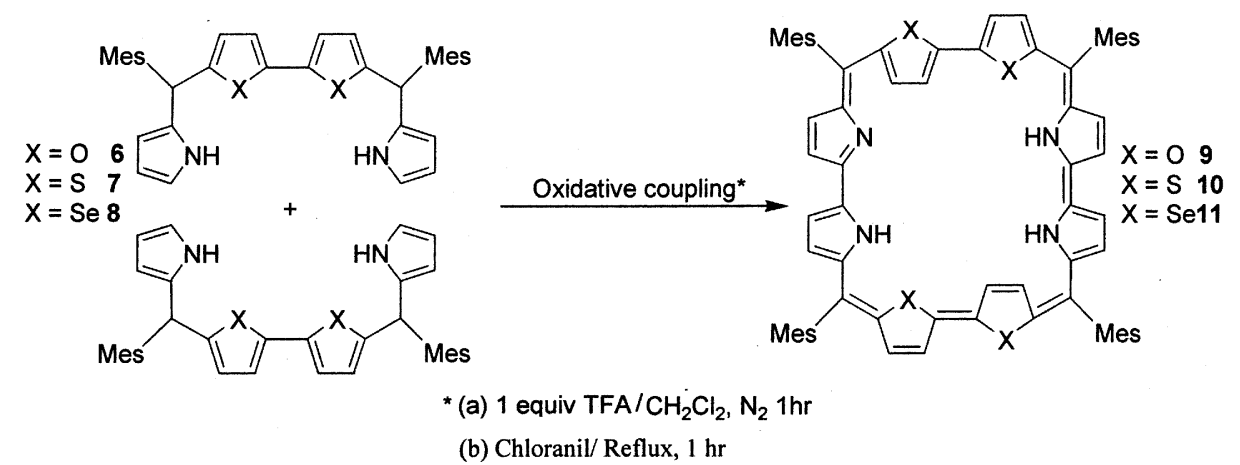

Scheme 1. Synthesis of planar, aromatic $34 \pi$-octaphyrin.

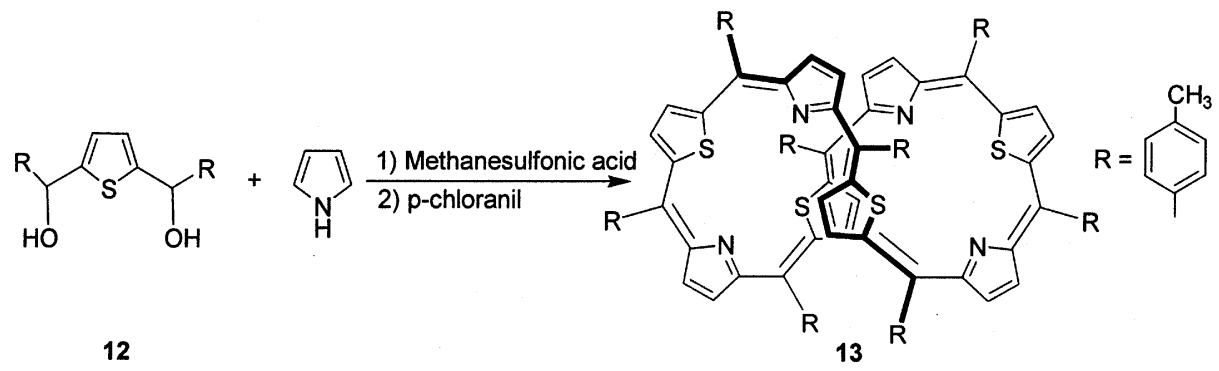

Scheme 2. Synthesis of "figure eight" octaphyrin.

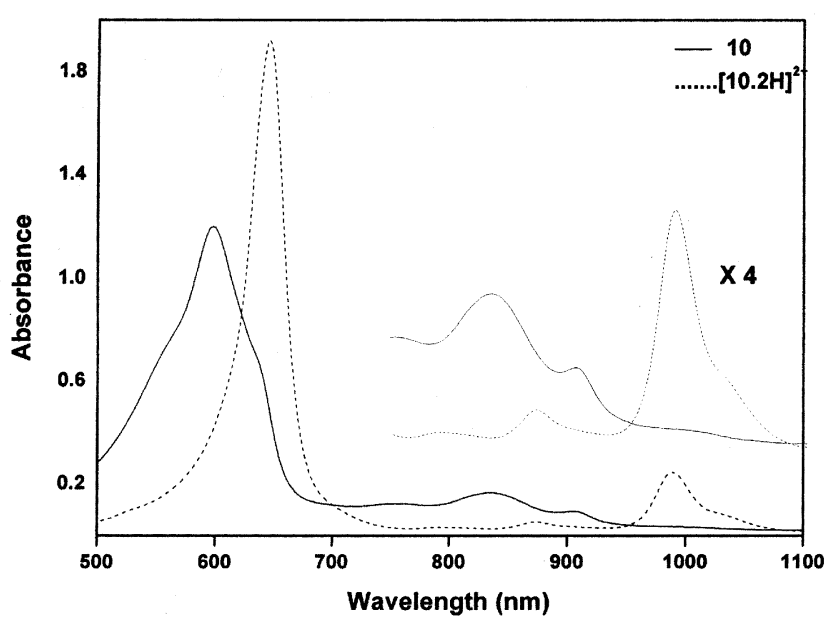

Figure 3. A comparison of absorption spectra of $\mathbf{1 0}(-)$ and $\left[\mathbf{1 0} . \mathrm{H}_{2}\right]^{2+}(\ldots)$ in $\mathrm{CH}_{2} \mathrm{Cl}_{2}$.

expanded porphyrins leads to formation of dications, which bind to anions through electrostatic interaction. Sessler and co-workers first reported the anion binding of protonated sapphyrin. Later, anions like fluoride, chloride, phosphate, azide, carboxylate etc. were found to bind protonated sapphyrins ${ }^{12}$ in particular and protonated expanded porphyrins in general. ${ }^{13}$
The anion-binding ability of core modified octaphyrins 9 and 11 was also examined in both solution and solid state. However, unresolved resonances in ${ }^{1} \mathrm{H}$ NMR of anion complexes prevented quantitative evaluation of binding constants. In the solid state under acidic conditions, we were successful in getting good quality crystals for single crystal X-ray determination of anion complexes. Both the octaphyrins 9 and 11 were found to bind TFA in $1: 2$ ratio. Novel binding modes of TFA by the macrocycles were observed with the octaphyrins mentioned above. Two TFA molecules bind to the octaphyrin, one above and one below the plane of the mean macrocyclic plane defined by four meso carbons of the macrocycle. Furthermore, the planarity of the macrocycle 11 gets slightly distorted on its complexation with TFA. Four hydrogen bonds are responsible for binding of TFA to octaphyrin (scheme 3 ). They are the following: (1) N-H...O: $2.232 \AA, 143.67^{\circ}$; (2) N-H...O: $2 \cdot 139 \AA, 146 \cdot 64^{\circ}$; (3) C-H...O: $2 \cdot 444 \AA$, $171 \cdot 04^{\circ}$; (4) C-H...F: $2 \cdot 323 \AA$, $146 \cdot 22^{\circ}$.

Out of the four hydrogen bonding interactions observed, the first two $\mathrm{N}-\mathrm{H}$... O interactions are the most common ways of anion binding to expanded porphyrins through electrostatic interactions. They 


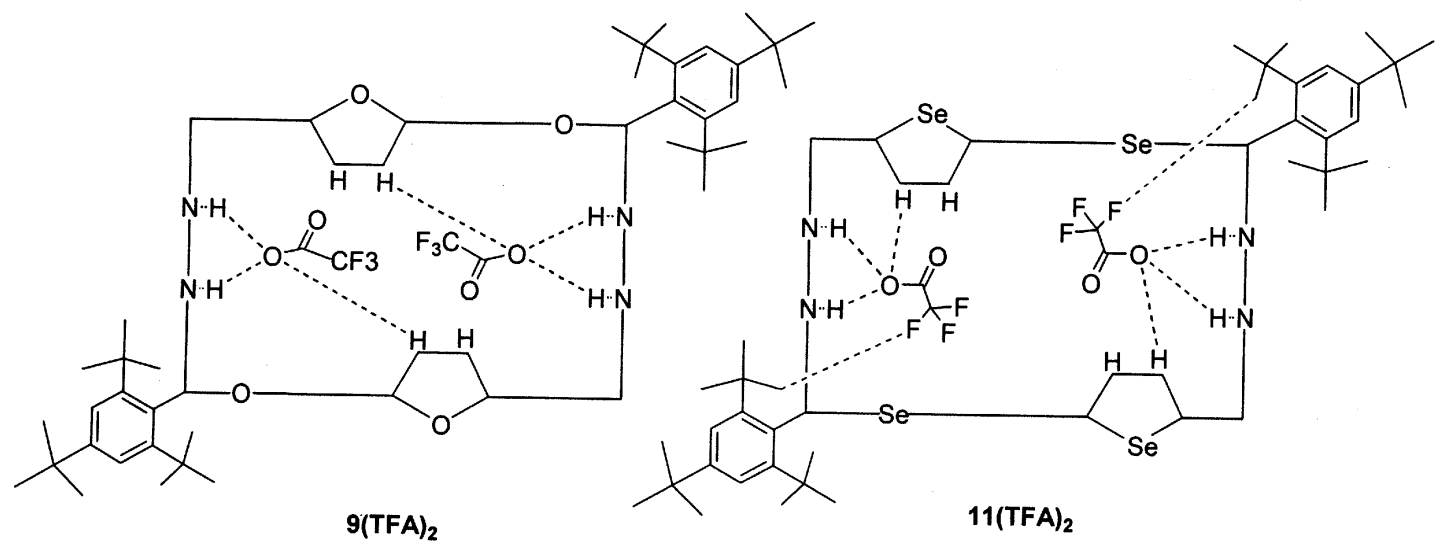

Scheme 3. Different modes of TFA binding to octaphyrins 9 and 11 .

are formed due to the protonation of the imino nitogens of the pyrroles by TFA. On protonation by TFA, the pyrrole rings of the bipyrrole unit are pulled above and below the macrocyclic plane depending on the side from which TFA is bound to the octaphyrin. Importantly, the involvement of $\beta-\mathrm{CH}$ protons in co-ordinating to the anion in the macrocycle was found for the first time. Even though ring-inverted expanded porphyrins are known to bind anions, the $\beta-\mathrm{CH}$ protons of the inverted ring were not known to be part of the anion-binding protocol. The proton of the inverted ring of selenophene from the biselenophene unit forms a secondary interaction (non-electrostatic) with oxygen of the TFA. Apart from the oxygen, the fluorine of the triflate anion also forms secondary interaction with the proton of the methyl group of the mesityl ring.

Tetraoxaoctaphyrin 9 also binds two TFA molecules, one above and one below the plane of the molecule. The distortion of octaphyrin plane in $\mathbf{9}$ was found to be very minimal in comparison to 11. TFA is held to the macrocycle by three hydrogen bonding interactions. They are (1) N-H...O: $2 \cdot 142 \AA, 142.43^{\circ}$; (2) N-H...O: $2.057 \AA$, $139.66^{\circ}$; (3) C-H...O: $2.335 \AA$, $149 \cdot 30^{\circ}$. Of the three hydrogen bonds, two are classical $\mathrm{NH}$ bond interactions and the third is a nonelectrostatic $\mathrm{C}-\mathrm{H}$... O bond. All the three bonds are formed with the same oxygen atom of the TFA molecule, while the other oxygen $(\mathrm{C}=\mathrm{O})$ is not involved in any of the secondary interactions. The involvement of bifuran in anion binding is different from that observed for $\mathbf{1 1}$ (TFA) $)_{2}$. In the case of tetraselena octaphyrin $\mathbf{1 1}$, the $\beta-\mathrm{CH}$ of the ring adjacent to the anion bound bipyrrolic unit forms the hydrogen bond with TFA. Whereas in 9 (TFA) $)_{2}$ the $\beta-\mathrm{CH}$ of the inverted furan binds to the anion which is bound to the non-adjacent bipyrrolic unit (scheme 3). The bifuran unit undergoes rearrangement such that the noninverted ring adjacent to the anion-bound bipyrrole is pushed away from the cavity of the macrocycle, making more room for the inverted furan ring to enter the cavity. Owing to this effect, the inverted furan ring is pulled towards the opposite bipyrrole unit, such that the proton of the inverted furan ring comes in close proximity to the TFA bound to the opposite bipyrrolic unit, rather than to the adjacent bipyrroles. The binding of TFA to the bipyrrolic units slightly pushes the pyrrole rings above or below the plane of the macrocycle depending on the side on which TFA is bound to the macrocycle.

\section{Conclusion}

In this paper, a brief review of the syntheses and anion-binding properties of core-modified octaphyrins is presented. Octaphyrins bind anions in a $1: 2$ ratio. Oxidative coupling of appropriate precursors under acidic conditions has become an attractive strategy for the higher aromatic expanded porphyrins. Studies on syntheses and anion-binding properties of higher order porphyrins are in progress.

\section{Acknowledgement}

This work was supported by grants from the Department of Science and Technology (DST) and the Council of Scientific and Industrial Research (CSIR), 
Government of India, New Delhi. RM and HR thank the CSIR for their fellowships.

\section{References}

1. (a) Vogel E, Broring M, Fink J, Rosen D, Schmickler H, Lex J, Chan K W K, Wu Y D, Plattner D A, Nendel M and Houk K N 1995 Angew. Chem., Int. Ed. Engl. 34 2511; (b) Broring M, Jendrny J, Zander L, Schmickler H, Lex J, Wu Y D, Nendel M, Cheng J G, Plattner D A, Houk K N and Vogel E 1995 Angew. Chem., Int. Ed. Engl. 34 2515; (c) Werner A, Zander M L, Lex J and Vogel E 1999 Angew. Chem., Int. Ed. 383650

2. Setsune J, Katakami Y and Lizuna N 1999 J. Am. Chem. Soc. 1218957

3. Sessler J L, Seidel D and Lynch V 1999 J. Am. Chem. Soc. 12111257

4. Shin J Y, Furuta H, Yoza K, Igarashi S and Osuka A 2001 J. Am. Chem. Soc. 1237190

5. Seidel D, Lynch V and Sessler J L 2002 Angew. Chem., Int. Ed. Engl. 411422

6. Anand V G, Pushpan S K, Venkatraman S, Dey A, Chandrashekar T K, Joshi B S, Roy, Teng W and Senge K R 2001 J. Am. Chem. Soc. 1238620
7. Anand V G, Venkatraman S, Rath H, Chandrashekar T K, Teng W and Senge K R 2003 Chem. Eur. J. 9 2282

8. Sprutta N and Grazynski L 2001 Chem. Eur. J. 7 5099

9. Anand V G, Pushpan S K, Venkatraman S, Narayanan S J, Dey A, Chandrashekar T K, Roy R, Joshi B S, Deepa S and Sastry G N 2002 J. Org. Chem. 67 6309

10. Chandrashekar T K and Venkatraman S 2003 Acc. Chem. Res. 36676

11. (a) Sessler J L and Weghorn S J (eds) 1997 Expanded, contracted and isomeric porphyrins (Oxford: Elsevier); (b) Jasat A and Dolphin D 1997 Chem. Rev. 97 2267; (c) Sessler J L, Gebauer A and Weghorn S J 2000 In The porphyrin handbook (eds) K M Kadish, K M Smith and R Guilard (New York: Academic Press)

12. (a) Iverson B L, Shreder K, Karl V, Smith D A, Smith J and Sessler J L 1994 Pure Appl. Chem. 66 845; (b) Sessler J L, Hoehner M C, Gebauer A, Andrievsky A and Lynch V 1997 J. Org. Chem. 62 9251; (c) Sessler J L and Davis J M 2001 Acc. Chem. Res. 34989

13. Narayanan S J, Sridevi B, Chandrashekar T K, Vij A and Roy R 1999 J. Am. Chem. Soc. 1219053 